\title{
How a buildup of abnormal proteins in the brain may be the key to understanding Alzheimer disease
}

Steven Karceski, MD

Neurology ${ }^{\circledR}$ 2020;95:ee2951-e2953. doi:10.1212/WNL.0000000000011044

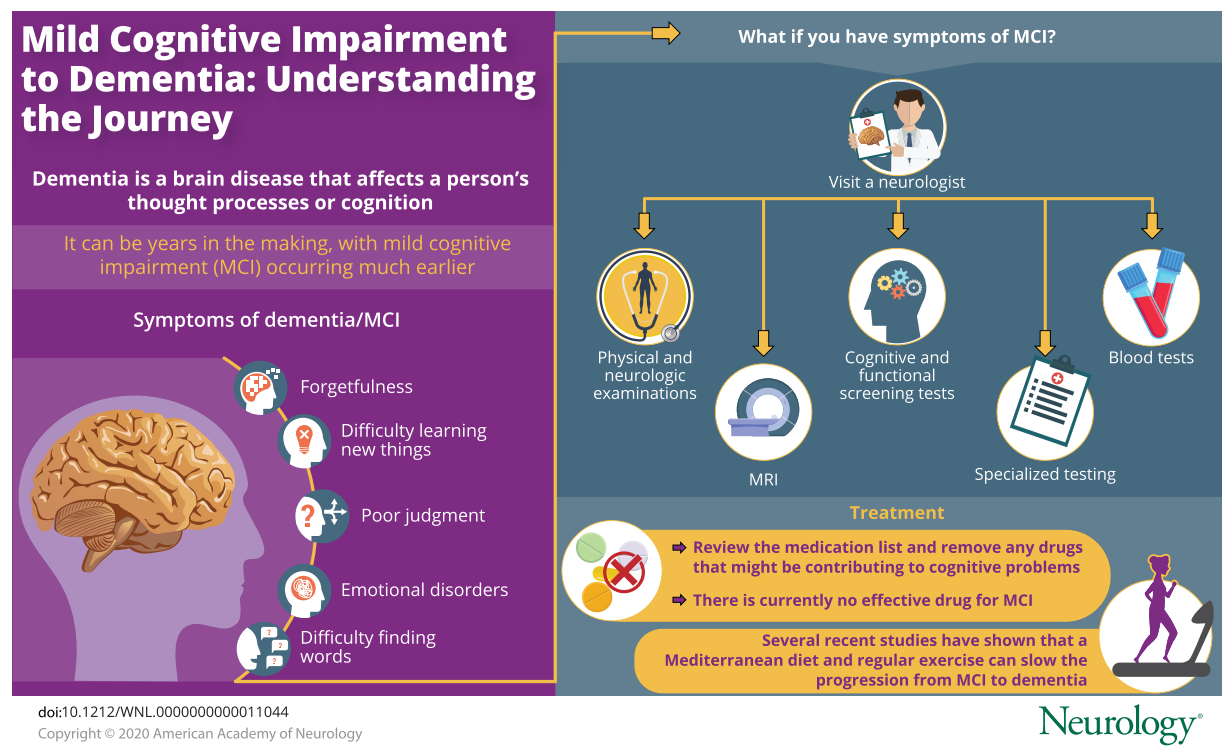

The term dementia describes a condition that causes trouble with thinking. The term does not tell us the cause of the problem. As scientists have studied dementia, they have identified many possible causes. For instance, if a person has had many brain injuries in life, he or she may develop problems with thinking. This type of dementia used to be called dementia pugilistica, which basically means dementia caused by fighting. This type of problem has been known to occur in boxers. However, this is not a common cause of dementiaafter all, most people are not professional fighters. In the majority of people with dementia, the 2 most common causes are Alzheimer disease (AD) and multi-infarct dementia (MID).

MID is caused by the gradual accumulation of damage to the brain from very small strokes. Although there are several causes of these strokes, the most common are high blood pressure or diabetes. Effective treatment of these causes has been shown to dramatically affect the chance of developing stroke later on. This is one of the reasons doctors are so aggressive in treating high blood pressure or diabetes: keeping them under control prevents other, very serious problems.

When meeting a person who has dementia, it can be difficult to determine the cause based on an examination alone. This is where medical testing is important. Using brain imaging, like MRI or PET, can help the doctor to better understand why the person is having trouble with thinking or memory. Through MRI, the doctor can see multiple small strokes that have occurred. Specialized PET scans can show the accumulation of amyloid $\beta(A \beta)$, an abnormal protein that builds up in AD.

The idea that brain imaging answers the question, however, is an oversimplification. It makes it seem as though the medical test can clearly show that the cause of the problem is either AD or MID. The reality is more complicated. There is some evidence that multiple small strokes may also contribute to the buildup of $A B$. Diagnosis becomes even more
Related Article

Brain amyloid $\beta$, cerebral small vessel disease, and cognition: A memory clinic study

http://dx.doi.org/10.1212/ WNL.0000000000011029 
complicated if we consider the possibility that a person may have both problems. Some studies suggest that for half of people with dementia (47\%), the dementia is due to more than one cause. ${ }^{1}$ What if the patient has AD, but also has small strokes due to long-standing high blood pressure? How can we separate the two?

\section{The medical study}

In their article "Brain amyloid $\beta$, cerebral small vessel disease, and cognition: A memory clinic study," Dr. Saridin and colleagues $^{2}$ tried to answer this question. Dr. Saridin works at the National University of Singapore, where there is a Memory, Aging, and Cognition Center. In the study, the authors looked at a group of people, all of whom had received specific medical testing designed to understand the cause of their complaints. They evaluated several factors, but also looked for strokes with MRI, as well as the accumulation of the protein $A \beta$ with PET. In this way, they were able to better understand how strokes and $A \beta$ contribute to dementia.

\section{How was the study done?}

Dr. Saridin and colleagues gathered 186 people who had been seen at the Memory Clinic. For the study, the authors divided the group into 4 categories: no cognitive impairment ( $\mathrm{NCl}$; this group is the comparison group, as they had no cognitive problems), cognitive impairment no dementia (CIND), AD, and vascular dementia (VaD). All of the people who participated in the study had undergone a detailed neurologic examination, as well as in-office memory testing. In addition, they had had more detailed cognitive testing, called neuropsychological testing. All had a 3 Tesla (Tesla measures the strength of the MRI: stronger MRI means a more detailed image) MRI of the brain. They also each had a specialized PET scan. The researchers used specialized computer programs to measure the severity of both stroke and $A \beta$ for each person.

\section{Who were the people in the study?}

All 186 people were involved in a study at the National University Hospital, Singapore. The study was designed to evaluate memory problems. The authors defined each of the 4 categories beforehand: normal $(\mathrm{NCI})$, mildly impaired (CIND, which is very similar to mild cognitive impairment $[\mathrm{MCl}]$, described in more detail below), and dementia due either to AD or multiple strokes (which they called VaD). On average, the age of the study participants was 75.6 years. A total of $53.8 \%$ were women. There was no difference between the groups in terms of other medical illnesses such as high blood pressure, diabetes, or high cholesterol, all of which can contribute to strokes.

\section{What did they find?}

First, Dr. Saridin found that more $A \beta$ was associated with more severe thinking problems in the people who had had no prior stroke. This association was independent of age, level of education, hippocampal volume (the hippocampus is a structure in the brain that is important to memory formation), and signs of small stroke. However, they also found increased $A \beta$ in the group who had VaD. They proposed that the cause of the increase was the strokes themselves. $A \beta$ is a protein that the brain constantly clears. However, when someone has a stroke, the brain is injured. This prevents the brain from clearing the $A \beta$, allowing for a gradual buildup of this protein.

\section{Why is this important?}

Based on this study, it seems the accumulation of $A \beta$ has a direct effect on a person's thinking. This connection could be very important in the development of treatments for dementia. Can we develop a medicine, for instance, that encourages the brain to clear the $A \beta$ ? Is there a way to prevent its formation? If not a medication, is there a special diet or a regimen of exercise that helps? All of these could help to prevent or treat one of the most serious problems we face as people get older.

\section{About mild cognitive impairment and dementia}

\section{What is mild cognitive impairment (MCl)? What is dementia?}

Unlike stroke, which happens suddenly, dementia starts much more slowly. Dementia can progress at a snail-like pace. Modern research suggests that dementia is an illness that is literally years in the making. A person who develops dementia starts out with normal thinking. Early on, the cognitive problems may be very subtle. Misplacing keys, forgetting appointments, and mixing up details (like in a recipe) are very common. Early on, a person may attribute these problems to "just getting older." There is truth to this idea. Studies show that as we get older, cognitive functions are slower. Learning new things becomes more difficult.

In normal aging, the problems stop there. But when a person has dementia, the cognitive function continues to get worse. At first, the problem is mild. At this stage, it is called $\mathrm{MCl}$. As the disease worsens, a person has an increasingly harder time performing complex brain tasks. At some point, the thought processes become so impaired that the person can no longer complete usual daily activities. Cooking, and the planning that is required to accomplish such a task, becomes harder. Tasks like keeping track of bills, appointments, and friends' names get harder. It is at the point when the problem significantly affects the person's daily life that we use the term dementia.

By definition, dementia is a brain disease that affects a person's thought processes. Memory is just one of the brain functions interrupted by dementia. Dementia can also affect judgement, emotions (mostly, dementia can cause depression), and language (such as trouble finding the right word to say). There are many different causes of dementia. Of these, AD is the most common. Because of this, people often use the terms dementia and AD interchangeably.

\section{Mild cognitive impairment}

When a person suspects he or she has thinking or memory troubles, seeing a neurologist is very important. Neurologists 
are trained to identify the features of $\mathrm{MCl}$ and $\mathrm{AD}$. With regard to $\mathrm{MCl}_{1}^{3,4}$ there are several things a neurologist will look for. First, the neurologist will need to meet with the person (and family members) to discuss the extent and nature of the problem. Is the person taking a medication that could affect thinking? How long has he or she been noticing a problem? Have there been any other neurologic problems, like past strokes? Have there been behavioral problems? The presence of these might suggest another problem altogether (not AD).

Often, a neurologist will request medical testing. The testing is designed to accomplish 2 main tasks. First, the tests may help support the diagnosis of $\mathrm{MCl}$. Second, the tests may help rule out other possible causes of memory or cognitive problems. One very common and well-studied test is called the Montreal Cognitive Assessment. This is a 10-minute test that has been shown to quickly and accurately determine whether a person is experiencing cognitive problems. Blood testing helps eliminate possible endocrine problems, like thyroid disease, which can cause trouble with clear thinking. However, neuroimaging, like MRI, does not provide a diagnosis. Instead, MRI is useful in identifying other neurologic problems that may look like dementia or AD.

The neurologist may also request other, more specific medical tests. For example, there is a brain test that can measure brain cell metabolism. This test is called a fluorodeoxyglucose PET, or FDG-PET. The FDG-PET shows regions of abnormal brain metabolism. The pattern of abnormal metabolism can suggest that the $\mathrm{MCl}$ is more likely to be caused by AD. A lumbar puncture may also be performed (sometimes known as a spinal tap). This test, which analyzes CSF, can show certain proteins that are more likely to be found in AD. That being said, lumbar puncture is not a standard test for $\mathrm{MCl}$ or $\mathrm{AD}$. It is performed only in specific instances, under the direction of the neurologist.

\section{What can be done about MCl? Can we prevent or slow dementia?}

Using the Internet, people can search for ways to improve memory and cognitive function. A quick search seems to suggest that there are many ways to either improve cognition or slow the development of AD. However, rigorous clinical trials have shown that there is no benefit from overthe-counter anti-inflammatory medications such as naproxen. Likewise, ginkgo biloba, vitamin $\mathrm{E}$, and vitamin C seem to have no benefits for thinking or memory. One study looked at possible benefits of nicotine on memory, but it found no effect. Another looked at the benefits of injected growth hormone-again, there was no long-term benefit. One thing that does seem to help, though, is exercise. Routine exercise appears to help cognition, and it may also slow the progression of AD. Anticholinesterase medications can also help, but their effect is small, and may be short-lived.

\section{What if I have memory problems? What should I do?}

Meeting with a neurologist is a very important part of the process. A neurologist can perform tests both in and out of the office that will help to better understand the cause of the memory problem. Testing narrows the list of possible causes. The neurologist can then identify treatments that are most likely to help. A neurologist can answer questions about memory problems, and about medical treatments. He or she can also dispel myths regarding misinformation gleaned from the Internet. The neurologist will likely recommend continued medical visits. This helps to monitor the problem and its response to treatment.

\section{For more information}

Brain \& Life

brainandlife.org

Alzheimer's Association
alz.org/

Lewy Body Dementia Association

lbda.org/

National Institute of Mental Health

nimh.nih.gov/index.shtml

\section{References}

1. Liu W, Wong A, Law AC, Mok VC. Cerebrovascular disease, amyloid plaques, and dementia. Stroke 2015;46:1402-1407.

2. Saridin FN, Hilal S, Villaraza SG, et al. Brain amyloid $\beta$, cerebral small vessel disease, and cognition: a memory clinic study. Neurology 2020;95:e2845-e2853.

3. Langa KM, Levine DA. The diagnosis and management of mild cognitive impairment: a clinical review. JAMA 2014; 312:2551-2561.

4. Jongsiriyanyong $S$, Limpawattana P. Mild cognitive impairment in clinical practice: a review article. Am J Alzheimers Dis Other Demen 2018;33:500-507. 


\section{Neurology}

\section{How a buildup of abnormal proteins in the brain may be the key to understanding Alzheimer disease \\ Steven Karceski \\ Neurology 2020;95;e2951-e2953 \\ DOI 10.1212/WNL.0000000000011044}

This information is current as of November 23, 2020

Updated Information \& Services

References

Permissions \& Licensing

Reprints including high resolution figures, can be found at: http://n.neurology.org/content/95/21/e2951.full

This article cites 4 articles, 2 of which you can access for free at: http://n.neurology.org/content/95/21/e2951.full\#ref-list-1

Information about reproducing this article in parts (figures,tables) or in its entirety can be found online at:

http://www.neurology.org/about/about_the_journal\#permissions

Information about ordering reprints can be found online: http://n.neurology.org/subscribers/advertise

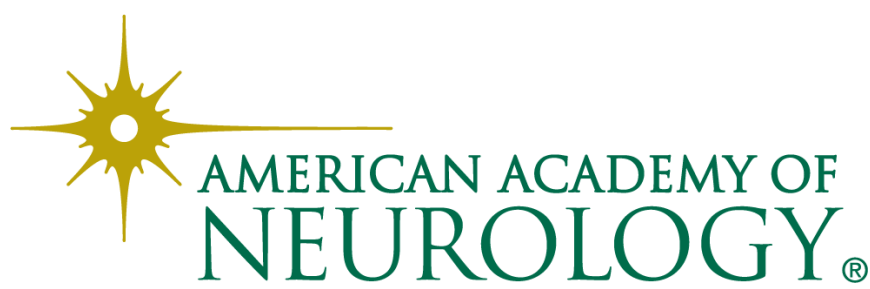

